\title{
Farmers' mental models of soil fertility in a semi-arid area of Kenya
}

\author{
Yoshie Yageta $^{1}$, H Osbahr ${ }^{2}$, Yasuyuki Morimoto ${ }^{3}$, and Joanna Clark² \\ ${ }^{1}$ Overseas Agricultural Development Association \\ ${ }^{2}$ University of Reading \\ ${ }^{3}$ Bioversity International
}

June 17, 2021

\begin{abstract}
Effective knowledge exchange between farmers and other stakeholders, such as agricultural extensionists and soil scientists, is essential for increasing opportunities for sustainable soil fertility management. To achieve this, it is necessary to understand local farmers' conceptualisation of soil fertility. This study visualizes farmers' perceptions of soil fertility as mental models, in order to explore the expansion of their soil knowledge and the extent of their comprehension of the relationship between soil properties that are seen and measured and soil processes. Aggregated mental models of fertile and low fertility soils were created from data collected from 59 farmer interviews at two villages in Kitui County, Kenya. The share of respondents of each concept were shown to analyse the knowledge gaps among farmers and between villages. The mental models revealed that farmers recognize the important roles of soil texture, water availability and farm management in soil fertility. Their knowledge related to their lived experience of the actual productivity of soils, which resulted in a strongly different perspective of fertile and low fertility soil. The differences of perception between the villages were also recognized as the result of differences in land availability. Although the farmers who mentioned soil processes were very few, farmers had the potential to integrate further soil scientific knowledge. Consequently, using the mental model approach to visualize farmers' perceptions produced benefits by clarifying understanding of farmers' knowledge and identifying gaps where soil science and extension work could help to expand farmers' knowledge.
\end{abstract}

\section{Hosted file}

May2021_LDD_manuscript_YYageta.docx available at https://authorea.com/users/420174/articles/ 526539-farmers-mental-models-of-soil-fertility-in-a-semi-arid-area-of-kenya 


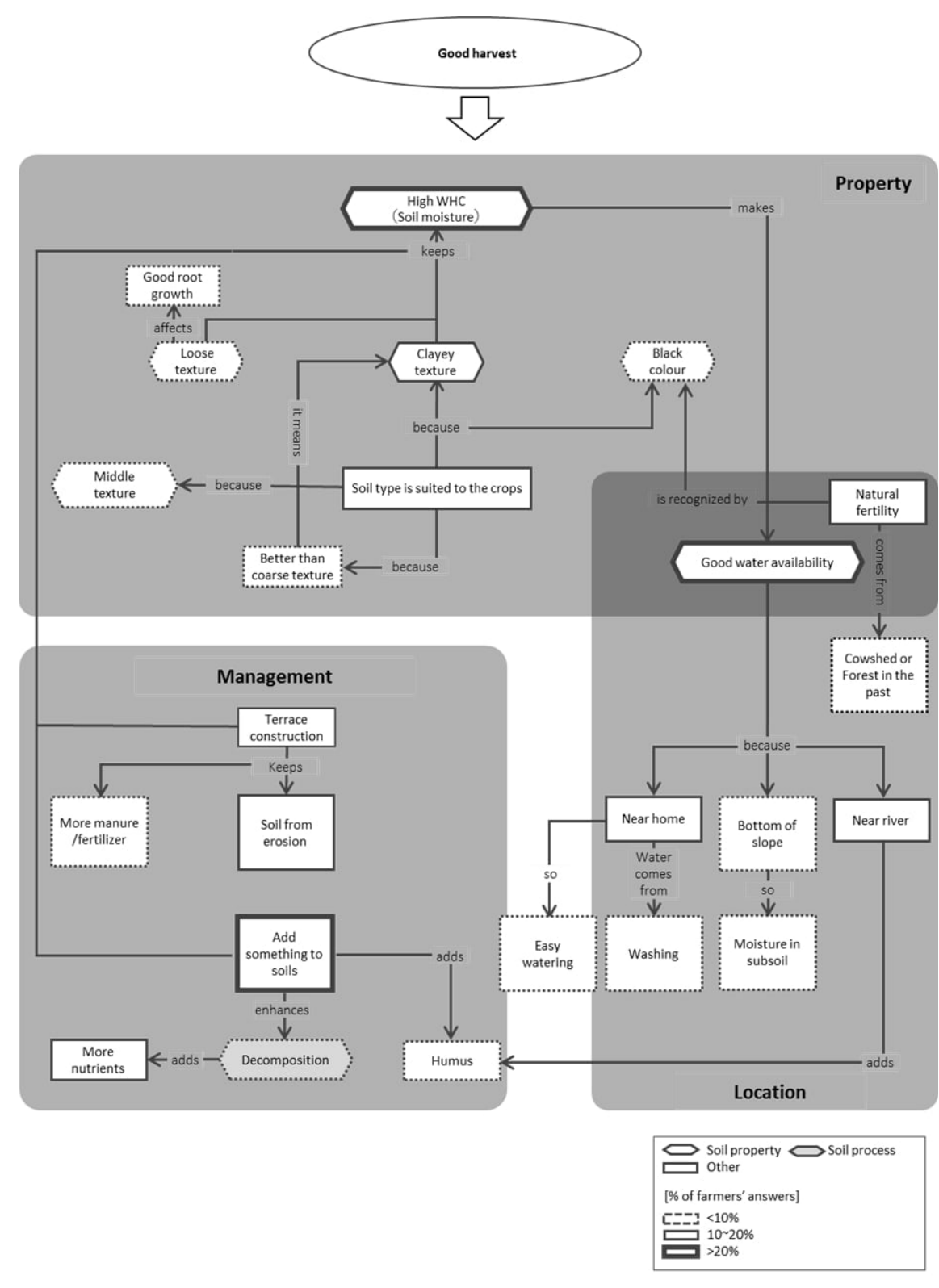




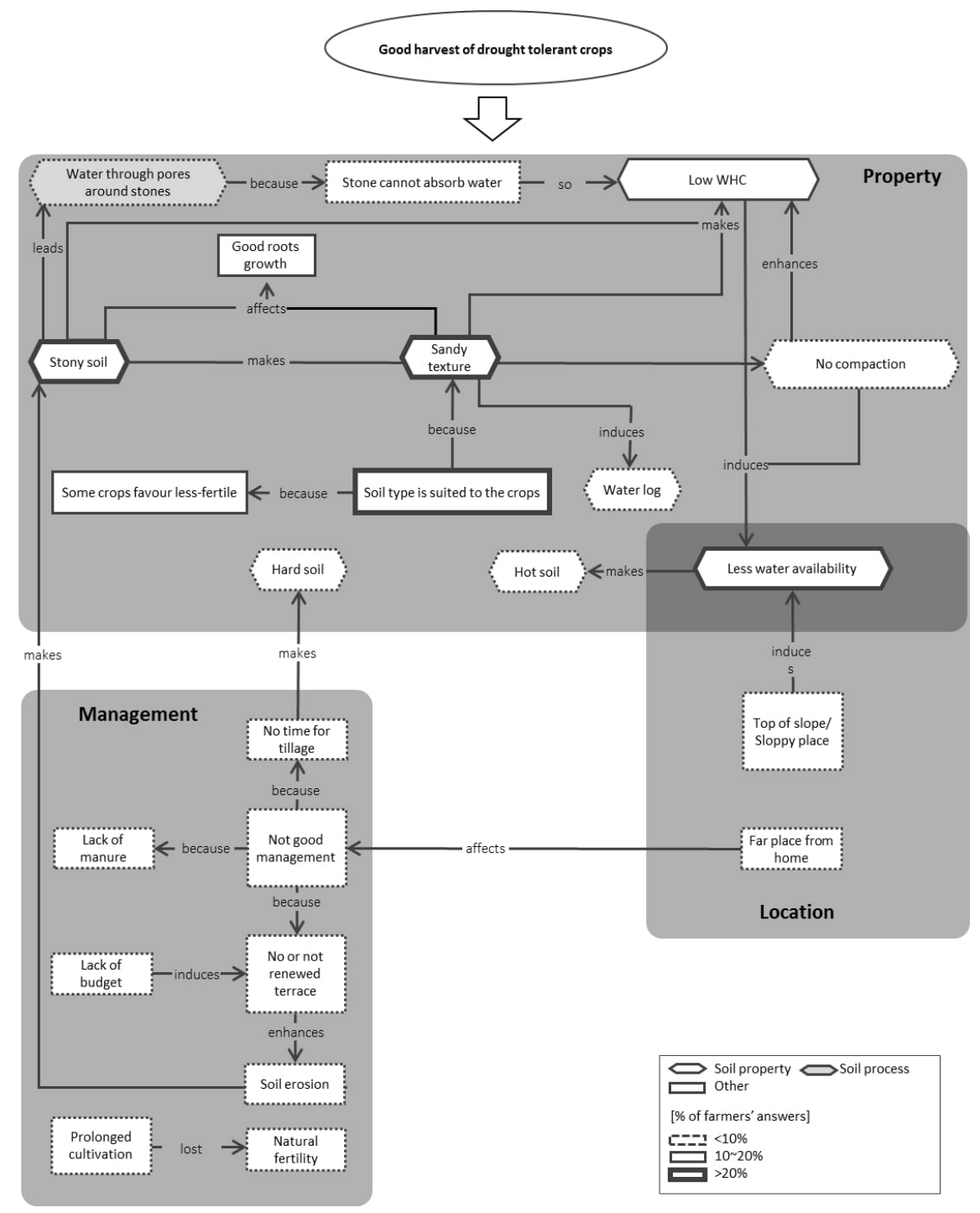

